\title{
Implications of Risk Evaluation and Mitigation Strategy (REMS) Programs for Managed Care Pharmacy
}

\author{
AMCP Special Projects Committee
}

I $\mathrm{n}$ the last 2 decades, health care management has been challenged by more aggressive therapy, the increased number of specialty medications, and more stringent guidelines to monitor adverse events or health risk. To promote patient safety, various communication requirements are mandated to increase the risk awareness of patients and physicians. These include black-box warnings, "Dear Health Care Provider" letters, U.S. Food and Drug Administration (FDA) Talk Papers, MedGuides, and Risk Minimization Action Plans (RiskMAPs).

Additional risk communication tools may be required by the FDA as authorized by the Food and Drug Administration Amendments Act (FDAAA) in 2007. ${ }^{1}$ This law empowered the FDA with new authority to better manage safety concerns of drugs by requiring Risk Evaluation and Mitigation Strategy (REMS) programs for both new and existing products. ${ }^{2}$ REMS programs often require safety communication to both health professionals and patients. Some medications may require additional tools to ensure safety. Additionally, the FDAAA states that the program shall not be "unduly burdensome on patient access" and shall "minimize the burden on the health care delivery system."1 In this commentary, we discuss the history of REMS, the specific requirements of REMS programs, and the roles of managed care organizations (MCOs), pharmacists, and pharmacies in executing REMS programs.

\section{History of REMS}

Prior to the FDAAA, health care provider risk communication programs had variable success rates in guiding appropriate prescribing and monitoring procedures., ${ }^{3,4}$ Although the FDA had the authority to require post-marketing commitments from manufacturers prior to drug approval, these commitments were not enforceable after approval. ${ }^{3}$ With some new therapies withdrawn from the market (e.g., rofecoxib in September 2004) ${ }^{5}$ or on restricted distribution due to serious side effects (e.g., natalizumab, which was temporarily withdrawn in February 2005, ${ }^{6}$ and thalidomide ${ }^{7}$ ), more FDA authority was deemed necessary to ensure the safe use of products in the marketplace.

To address this issue of patient safety, the authority to require REMS programs for medications or medication classes with known serious risks was granted to the FDA by FDAAA, effective on March 25, 2008. ${ }^{2}$ Through FDAAA, the FDA is given the authority to determine which drugs require a REMS program as part of the approval process or during the postapproval period in order to ensure that the benefits of using the drug outweigh its risk. The following considerations are required of the Secretary of Health and Human Services by the FDAAA when determining if a specific drug or biological product should have a REMS program associated with its approval: ${ }^{8}$

- The size and demographics of the population likely to use the drug

- The seriousness of the disease the drug is intended to treat

- The expected benefit of the drug in its indication

- The seriousness of any known or potential drug-related adverse events and the background incidence of these events in the intended population

- Whether the drug is a new molecular entity

\section{REMS Components}

The majority of REMS programs require safety communication to health care professionals, patients, or both. Special patient, pharmacy, and prescriber registries; restrictive specialty pharmacy distribution processes; or additional tools to ensure safety can be required for drugs with especially significant safety concerns. ${ }^{3}$ In addition to a requirement for assessment and modification of each approved REMS, there are 3 content sections: (1) timetable for submission of assessments, (2) additional potential elements, and (3) Elements to Assure Safe Use (ETASU). 8

Timetable for Submission of Assessments. All approved REMS programs for New Drug Applications (NDA) or Biologic License Applications (BLA) must have on file a timetable for the assessment of the REMS. Assessments must be made at 18 months and 3 years after the strategy is approved and at least 1 additional assessment in the seventh year after the REMS is approved, or at another frequency specified within the REMS. ${ }^{8}$ The assessments are designed to measure effectiveness, to ensure patient safety, and also to prove to the FDA that the REMS has achieved its goal to reduce drug risks. However, the FDA has not provided direction as to how or what should be assessed.

Additional Potential Elements. Additional elements in a REMS program may include the following:

Medication Guide. A medication guide describes potentially serious public health concerns about the medication. The medication guide is provided to the patient when a drug is dispensed. The FDA is authorized to require a medication guide "if FDA determines one or more of the following circumstances exist: 
(1) The drug product is one for which patient labeling could help prevent serious adverse effects.

(2) The drug product is one that has serious risk(s) (relative to benefits) of which patients should be made aware because information concerning the risks could affect patients' decision to use, or continue to use, the product.

(3) The drug product is important to health and patient adherence to directions for use is crucial to the drug's effectiveness."

Patient Package Insert. The FDA may require a patient package insert if it is determined this would help to mitigate serious risk. Typically a medication guide and a patient package insert would not be required in the same REMS.

Communication Plan. The FDA may determine that an element of REMS programs should be a plan to make critical information available to health care providers. A communication plan for prescribers may include distributing information about REMS program elements to health care providers and professional associations for adoption; describing safety protocols, including medical monitoring via laboratory tests; or sharing information about any serious adverse events associated with the medication and any additional measures to promote patient safety.

Dalfampridine is an example of a drug approved by the FDA with REMS requirements for both a medication guide and a communication plan. ${ }^{10}$ The manufacturer, Acorda Therapeutics, was required to implement a communication plan composed of letters to both prescribers and pharmacists, distributed within 60 days of the initial approval of dalfampridine, as well as follow-up letters to both groups sent within 60 days of the anniversary date of approval every year for the next 3 years. The "Dear Prescriber" letter is intended to educate prescribers about the proper distribution and safe use of dalfampridine. The letter describes the key risk messages of the REMS, including (a) increased seizure risk with doses over 10 milligrams (mg) twice daily; (b) "selection of the appropriate patient population, specifically those without seizure history and without moderate or severe renal impairment;" (c) the former names of dalfampridine including fampridine; (d) appropriate prescribing information; (e) information about pharmacy-compounded formulations including unknown pharmacokinetics and potential risks with therapeutic interchange; (f) warning not to use the compounded formulation in conjunction with dalfampridine; and (g) the importance of discontinuation of dalfampridine and prompt reporting to the manufacturer if a patient experiences a seizure. ${ }^{10}$ The timetable for submission of REMS assessments by Acorda was set by the FDA at 18 months, 3 years, and 7 years from the date of the REMS approval. ${ }^{10}$

Elements to Assure Safe Use. The FDA may also require that manufacturers develop a safety program with additional components, referred to as an ETASU. As defined in FDAAA, the elements of an ETASU may include 1 or more of the following: (1) "Health care providers who prescribe the drug must have particular training or experience, or are specially certified;

(2) Pharmacies, practitioners, or health care settings that dispense the drug are specially certified;

(3) The drug is dispensed to patients only in certain health care settings, such as hospitals;

(4) The drug is dispensed to patients with evidence or other documentation of safe use conditions, such as laboratory test results;

(5) Each patient using the drug is subject to certain monitoring; or

(6) Each patient using the drug is enrolled in a registry."

ETASU Implementation System. The FDA may require approval of an implementation system to monitor and evaluate ETASU execution. All stakeholders in the medication distribution process can be affected by ETASU and their associated implementation systems and may be required to take on additional responsibilities or alter processes, policies, and procedures to comply with the mandated program.

- The manufacturer must design the REMS, ensure its compliance, and report to the FDA on how well the REMS is meeting the safety objectives it was designed to address. Many manufacturers contract with a program administrator to collect and maintain data and provide support services to help oversee the REMS.

- Distributors and wholesalers could require certification, provide additional data, or credential pharmacies that can receive the drug as part of a REMS.

- Pharmacies may be called on to ensure that medication guides are distributed or that data elements are collected and often serve as the final check to make sure that the REMS requirements have been met.

- Physicians and nurses may be required to convey REMS messages to patients and ensure that patients are willing and able to comply with these messages. Physicians and nurses may also be called upon to complete additional educational or training programs, participate in a registry, or collect and report additional data elements prior to prescribing or administering.

- Patients can be engaged in the REMS process by requirements for periodic clinical testing, completion of additional educational elements, or receipt of a medication guide.

- MCOs strive to ensure appropriate use, align protocols, and design appropriate benefit structures within the context of the REMS program requirements and the impact of limited distribution for some drugs.

For example, Celgene, the manufacturer of lenalidomide (Revlimid), established the RevAssist program. ${ }^{12}$ Physicians who prescribe lenalidomide must be certified in the RevAssist program and provide counseling to patients for whom they 
prescribe the product. Prescribers must also sign an agreement with the patient and register the patient with the RevAssist program. Prescribers must provide contraceptive counseling if the patient is a female of child-bearing potential, as well as provide routine pregnancy testing. Prescribers must report any pregnancies and can prescribe only a 4 -week supply at a time with no telephone refills. Prescribers must then contact a RevAssist-contracted pharmacy to fill the patient's prescription. The RevAssist pharmacies must also provide counseling to the patients and notify the RevAssist program administrator (funded by the manufacturer Celgene) of each prescription to ensure it is appropriately registered and the prescription fill is recorded. Celgene is responsible for ensuring appropriate education of the physicians, pharmacists, and pharmacy staff. The RevAssist pharmacies are also responsible for close monitoring and follow-up with patients in various subgroups, particularly patients of child-bearing potential. In order to accomplish these requirements as well as some additional components, Celgene contracted with McKesson to administer the RevAssist program.

\section{REMS Developments}

REMS programs may address any type of prescription drug, including traditional therapies as well as biologic therapies, and may be required for new products and approved products already on the market. After the establishment of the REMS program requirements, the FDA approved 25 REMS programs in 2008. An additional 74 REMS programs were approved in 2009; 57 products had REMS programs approved in 2010, and 40 products had REMS programs approved in 2011. ${ }^{13} \mathrm{In}$ February 2011, the FDA released a guidance regarding the differences between stand-alone medication guides and medication guides as part of REMS. As a result of this FDA guidance, many active REMS programs were released from REMS requirements because the only component of the strategies was a medication guide that did not fall under the description of the FDAAA medication guide for REMS. ${ }^{9}$ As of February 15, 2012, 207 REMS programs included an element of REMS, and 103 of these REMS programs (50\%) were still active (Table 1$).^{13}$ Thirteen examples of recent REMS products with component parts are shown in Table 2. 14-28

REMS for Extended-Release Opioid Products. The specific requirements for REMS programs are updated based on evolving information available to the FDA and pharmaceutical manufacturers. For example, work on the FDA's classwide opioid REMS program began formally in February 2009, when the FDA invited sponsors of extended-release opioid products to a private meeting. ${ }^{14}$ In July 2010, the FDA released its draft of a REMS program for extended-release opioid products. The REMS program consisted of a medication guide, ETASU, and a timetable for submission of assessments. The ETASU included an educational program for prescribers and materi-

\section{TABLE 1 Number of REMS by Component: March 25, 2008, Through February $15,2012^{13}$}

\begin{tabular}{|c|c|c|c|c|}
\hline & $\begin{array}{l}\text { New } \\
\text { REMS } \\
\text { Approved }\end{array}$ & $\begin{array}{l}\text { REMS Still } \\
\text { Active on } \\
\text { February } 3 \\
\quad 2012\end{array}$ & $\begin{array}{l}\text { REMS with } \\
\text { Medication } \\
\text { Guide or } \\
\text { Communication } \\
\text { Plan or Both on } \\
\text { February 15, } \\
2012\end{array}$ & $\begin{array}{c}\text { REMS with } \\
\text { All } 4 \\
\text { Components }^{\mathrm{a}} \\
\text { on } \\
\text { February 15, } \\
2012\end{array}$ \\
\hline $\begin{array}{l}\text { Number } \\
\text { of drugs }\end{array}$ & 207 & 103 & 103 & 9 \\
\hline \multicolumn{5}{|c|}{$\begin{array}{l}\text { aThe } 4 \text { REMS components are (a) medication guide, (b) communications plan, } \\
\text { (c) ETASU, and (d) ETASU implementation system. } \\
\text { ETASU =Elements to Assure Safe Use; REMS = Risk Evaluation and Mitigation } \\
\text { Strategies. }\end{array}$} \\
\hline
\end{tabular}

als that prescribers can use to educate patients regarding the safe use, storage, and disposal of extended-release opioids. After years of debate and several public meetings, the FDA released the REMS program required for all extended-release opioid medications on April 19, 2011. The FDA action was taken in conjunction with the Office of National Drug Control Policy (ONDCP) release of "Epidemic: Responding to America's Prescription Drug Abuse Crisis," the Obama Administration's "comprehensive action plan to address the national prescription drug abuse epidemic.."14 In October 2011, the FDA released a "Blueprint for Prescriber Education for the Long-Acting/ Extended-Release Opioid Class-wide REMS," which advised that prescribers should be "aware of the existence of Patient Provider Agreements (PPAs), although FDA is not requiring their use."15 Although the goal is to decrease inappropriate and unsafe use of long-acting/extended-release opioid products and changes may be made in the final blueprint, the current version does not have a direct impact on MCOs.

\section{Pharmacy's Roles and Responsibilities in REMS}

Patient safety and risk containment via side effect management are 2 major cornerstones of pharmacy practice. Pharmacies and pharmacists play important roles in the administration and management of REMS programs, including the provision of educational materials, counseling, and valuable medication information for patients. Some of the pharmacy activities in supporting the REMS program may include the following:

- supplemental communication plans to alert physicians and patients of potential risks and to direct safe product use (e.g., reminders of the need for testing for latent or active tuberculosis infection in patients initiating or continuing treatment with tocilizumab) ${ }^{17}$

- provision of required medication guides to patients

- validating that patients are enrolled in a REMS database prior to dispensing

- pharmacy and pharmacist certification via training and 


\section{TABLE 2 Examples of Recent REMS ${ }^{a}$}

\begin{tabular}{|c|c|c|c|c|}
\hline Medication & $\begin{array}{l}\text { Medication } \\
\text { Guide }\end{array}$ & $\begin{array}{c}\text { Communication } \\
\text { Plan }\end{array}$ & ETASU & $\begin{array}{l}\text { Implementation } \\
\text { System }\end{array}$ \\
\hline Abstral (fentanyl) sublingual tablets ${ }^{16}$ & $\mathrm{X}$ & & $\mathrm{X}$ & $\mathrm{X}$ \\
\hline Actemra (tocilizumab) injection ${ }^{17}$ & & $\mathrm{X}$ & & \\
\hline Actiq (fentanyl citrate) oral transmucosal lozenge ${ }^{18}$ & $\mathrm{X}$ & & $\mathrm{X}$ & $\mathrm{X}$ \\
\hline Botox/Botox Cosmetic (onabotulinumtoxinA) ${ }^{19}$ & $\mathrm{X}$ & $\mathrm{X}$ & & \\
\hline Brilinta (ticagrelor) tablets 20 & $\mathrm{X}$ & $\mathrm{X}$ & & \\
\hline Caprelsa (vandetanib) tablets 21 & $\mathrm{X}$ & $\mathrm{X}$ & $\mathrm{X}$ & $\mathrm{X}$ \\
\hline Lumizyme (alglucosidase alfa) ${ }^{22}$ & & $\mathrm{X}$ & $\mathrm{X}$ & $\mathrm{X}$ \\
\hline Mifeprex (mifepristone) tablets 23 & $\mathrm{X}$ & & $\mathrm{X}$ & $\mathrm{X}$ \\
\hline Nulojix (belatacept) ${ }^{24}$ & $\mathrm{X}$ & $\mathrm{X}$ & & \\
\hline Perforomist (formoterol fumarate) 25 & $\mathrm{X}$ & $\mathrm{X}$ & & \\
\hline Prolia (denosumab) injection 26 & $\mathrm{X}$ & $\mathrm{X}$ & & \\
\hline Tikosyn (dofetilide) capsules 27 & $\mathrm{X}$ & & $\mathrm{X}$ & $\mathrm{X}$ \\
\hline Yervoy (ipilimumab) injection 28 & & $\mathrm{X}$ & & \\
\hline
\end{tabular}

education requirements in order to obtain authorization to dispense restricted prescription products (e.g., authorization to dispense bosentan as described in the next paragraph)

- pre-therapy testing requirements (e.g., iPLEDGE, a risk management program to reduce the risk of fetal exposure to isotretinoin. To obtain the drug, in addition to registering with iPLEDGE, women of childbearing age must comply with necessary pregnancy testing. $)^{29}$

- ongoing patient monitoring once drug therapy is initiated

The ETASU program for bosentan (Tracleer) is an example of a REMS program that requires pharmacy and pharmacist certification. The manufacturer, Actelion, is required to ensure that all dispensers of bosentan are specially certified, including pharmacies, practitioners, and health care settings where the product may be dispensed. ${ }^{30}$ The certification includes education of pharmacy staff on the REMS program procedures and materials as well as indicating that the pharmacy is aware that it may be audited at any time. Staff must ensure that the pharmacies accept the patient and prescriber enrollment forms only from PAH Pathways, the entity that administers the bosentan REMS program. Pharmacies must counsel patients on the risks of bosentan, the need to complete monthly liver function tests and pregnancy tests, the need to use reliable contraception during treatment and for at least a month following discontinuation, and the need to inform the prescriber if pregnancy is suspected. Pharmacies are required to verify the drug shipment address and dispense only a 30-day supply at a time. Pharmacies may dispense only to patients enrolled in the REMS program and must provide a medication guide to patients with every fill of bosentan. The pharmacist may not refill the prescription until he or she has spoken with either the patient or prescriber to verify that both liver function and preg- nancy tests were completed. Finally, the pharmacy is required to follow up on patients who discontinue or have stopped refilling bosentan to validate and determine the reason and record this information for the REMS program database. Pharmacies or other certified dispensing sites are required to notify Actelion of any adverse events and collect and report specific data to Actelion to ensure compliance with the program. ${ }^{30}$

Due to the complexity of these risk management requirements, pharmacies may employ data management systems and/or additional processes to ensure proper compliance with the REMS requirements. Some pharmacy practice settings may not be able to support all of the requirements, such as patient registries and ongoing monitoring. Pharmaceutical manufacturers often contract with specialty pharmacies or REMS Coordination Centers such as United BioSource Corporation or HealthBridge to administer and evaluate the complex requirements of some REMS programs. ${ }^{31}$ The REMS for ambrisentan (Letairis), for example, requires the manufacturer to certify "pharmacies, practitioners, and health care settings that dispense Letairis" and "audit all certified dispensers and the REMS Coordinating Center."32

While providing patients with new therapeutic options for debilitating or life-threatening conditions, many specialty pharmaceuticals or biologics require special clinical management to monitor potential health and safety risks. The REMS requirements for some biologics are extensive and patientspecific (e.g., patient-specific authorizations and inventory management, including requirements for patient registries) requiring close coordination between patient, prescriber, and wholesaler. For example, erythropoiesis-stimulating agents (ESA) epoetin alfa (Epogen, Procrit) and darbepoetin alfa (Aranesp) have REMS requirements that include all 4 components (medication guide, communication plan, ETASU, 
and an implementation system). ${ }^{13,33,34}$ The REMS goals for epoetin alfa and darbepoeitin alfa include (a) "support informed decisions between patients and their healthcare providers" who are considering treatment with these ESAs by educating them on the risks of these agents; and (b) "mitigate the risk of shortened overall survival and/or increased risk of tumor progression or recurrence" for treatment of patients with cancer via the ESA APPRISE (Assisting Providers and cancer Patients with Risk Information for the Safe use of ESAs) Oncology Program. ${ }^{33,34}$

REMS programs allow drugs with significant therapeutic benefit and potentially serious safety issues to be available to patients through careful risk management. As the specialty pharmaceutical pipeline continues to produce new therapies for many diseases and currently unmet clinical needs, a larger percentage of drugs will have complex and detailed REMS programs.

\section{REMS Effects on Payers}

The impact of REMS programs on MCOs and payers crosses several areas including determination of appropriate use; alignment of protocols, benefit structure, and utilization management criteria with the REMS program requirements; impact of limited distribution; and patient confidentiality under Health Information Portability and Accountability Act (HIPAA) requirements.

Limited Distribution Networks. Limited distribution networks, which may be part of the ETUSA protocol, have a significant impact on an MCO. When a manufacturer contracts with a small number of pharmacies (community, mail order, or specialty) to dispense a product, the pharmacies may not be in the MCO's pharmacy network. If an MCO plans to provide coverage for the medication, the MCO may need to enter into a separate contract with 1 or 2 pharmacies, potentially for a single product. There is an increased economic burden on the MCO associated with the administrative management of single product contracts as the number of products with REMS programs and limited distribution networks increases. ${ }^{35}$ When a health maintenance organization (HMO) pharmacy is not part of the limited distribution network, the prescriber is still required to follow the REMS requirements; however, the patient could acquire the drug elsewhere, from a pharmacy without access to the patient's electronic health record (EHR). This problem could potentially increase the risk of a medication error and/or drug interactions.

Integration of New REMS Programs for Existing Products. When a REMS program requirement is added for a product already on the market, the effects on MCOs can be complicated. ${ }^{36}$ MCOs may have utilization guidelines and/or protocols already in place and may need to update them in order to accommodate the new REMS program requirements. For example, many MCOs have prior authorizations (PA) on specialty or biologic products. The criteria are meant to ensure use according to FDA-approved indications, address safety concerns, and encourage formulary compliance to promote cost-effective therapy. However, a new REMS program for one of these medications may require the MCO to add criteria to the approval process, which may involve additional documentation, laboratory values, and prior history. This can lead to an increased administrative burden on the MCO to ensure that appropriate documentation is obtained. Formulary placement may also be affected, especially if the REMS program change applies to only 1 agent in a therapeutic category. Additional provider and patient education will be necessary to prevent access issues for patients who need the medications, as patients and providers must comply with the new REMS program requirements. Lastly, if the distribution system changes due to the REMS program requirement, patients may need to find a new pharmacy from which to obtain their medications. ${ }^{35}$ MCOs must be proactive to include at least 1 limited distribution pharmacy in their networks in order to minimize the impact on patient access and delays in treatment continuation. $^{35,36}$

For example, after rosiglitazone had been on the market for 11 years, the FDA and GlaxoSmithKline announced in 2010 that a REMS program would be put in place for rosiglitazonecontaining products. ${ }^{37}$ The purpose of this new restriction was to limit access to rosiglitazone-containing medicines to prescribers who acknowledge the potential risk of myocardial infarction associated with rosiglitazone use. It also was to ensure that access is limited to patients who are advised by a health care provider about the potential risks and are either already taking a rosiglitazone-containing medication or are unable to control their hyperglycemia on other medications and "have decided not to take pioglitazone for medical reasons." ${ }^{\text {37 }}$ Because the product was already on the market, GlaxoSmithKline had to send a "Dear Pharmacist" letter and a "Dear Healthcare Provider" letter detailing the REMS program requirements. GlaxoSmithKline implemented a system for limited distribution of the products through certified pharmacies, which required additional communications and ensuring that all current utilizers would continue to have access to the products. ${ }^{37}$

REMS Programs Involving Patient Data. Some REMS programs raise concerns about patient confidentiality. ${ }^{35}$ The REMS vendor requests a HIPAA waiver from the patient. After appropriate confidentiality documentation is provided, the MCO may need to provide data to the REMS vendor in order for the manufacturer to be able to meet its obligations to the FDA under the REMS requirements. Although MCOs are not mandated by the FDA to provide data to manufacturers or REMS vendors, ${ }^{8}$ many MCOs choose to do so for a reporting fee paid 
by the manufacturer or REMS vendor. This new relationship between MCOs and REMS vendors can present a challenge for some organizations. ${ }^{35}$ For closed HMO models, such as Kaiser Permanente, providing collected data to the manufacturer so that it can comply with a REMS mandate is a point of contention; these organizations are accustomed to keeping their data proprietary, but to participate in some REMS programs they will have to "agree to certain data reporting." ${ }^{35}$

On the other hand, the additional outcomes data collected through a REMS program may provide useful information to MCOs to allow them to evaluate the health impact of these therapies. Although MCOs can do this analysis with their own data, an individual MCO may not have an enrolled population of sufficient size to assess outcomes. To maximize the ability for plans to assess the health outcomes of a medication associated with a REMS requirement, a publicly available summary provided by the FDA of each product's REMS findings would be valuable. ${ }^{35}$ One such example where the FDA informed the public about data collected through a REMS program is the Tysabri (natalizumab) TOUCH (Tysabri Outreach: Unified Commitment to Health) program, which aims to minimize the risk of progressive multifocal leukoencephalopathy (PML). Through the FDA's reporting, MCOs are better able to assess the overall risk to the patient population, currently 201 cases of PML reported among 96,582 patients treated with natalizumab worldwide through January 4, 2012.38 In addition, through close monitoring of the natalizumab REMS program, the FDA has also been able to determine additional risk factors that can increase a patient's chances of developing PML, such as presence of anti-JC virus antibodies, longer duration of natalizumab treatment (particularly more than 2 years), and prior treatment with an immunosuppressant medication. ${ }^{38}$ Insights released by the FDA and gained through a REMS program allow MCOs to evaluate data from a larger population and incorporate this information into MCO decision making (e.g., formulary development and programs for patient safety and utilization management).

Assistance in Determining Appropriate Use. One of an MCO's primary goals in management of the pharmacy benefit is to ensure appropriate medication use. REMS programs can serve a purpose similar to those of PAs and step-therapy requirements by ensuring that only clinically appropriate patients are allowed to receive a particular drug therapy. However, the manufacturer has an FDA mandate to perform REMS administration and bear the associated cost, whereas MCOs administer and bear the costs of PA and step-therapy programs. REMS programs can also result in heightened attention to fraud, waste, and abuse prevention, such as in the long- acting opioid REMS programs and the new classwide REMS program for transmucosal immediate release fetanyl (TIRF) drugs. ${ }^{14,16}$ Additionally, REMS interventions could potentially result in fewer adverse events, although there is no published evidence of this effect.

REMS programs are designed to mitigate a drug's specific risks but may not limit the indications for which a product can be prescribed, especially if the REMS requirements are a medication guide and communication plan (and not an ETUSA). Given the potential risks of medications even with REMS program requirements, MCOs may need to implement additional utilization management criteria to ensure appropriate use. In one MCO example, RegenceRx developed medical necessity criteria for dalfampridine (Ampyra) for improvement of walking in patients with multiple sclerosis (MS), which went beyond the communication provided by the REMS program. ${ }^{39}$ The FDA-approved dalfampridine REMS program consists of a medication guide and a communication plan with the goal of informing providers of the risk of drug-associated seizures with dalfampridine. ${ }^{10}$ As a result of the MCO's review of the clinical and safety data, it approves coverage requests for dalfampridine based on monitoring parameters of increased walking speed in patients with MS and ability to ambulate at least 25 feet, among other requirements for medical necessity. ${ }^{39,40}$ By providing additional resources to patients and health care providers and by limiting distribution to maximize the likelihood that the benefits of a medication outweigh its risks for an individual patient, REMS programs can mitigate patient safety risks. However, MCOs may need to add patient safety criteria to the clinical evaluation and formulary decision processes, and utilization management programs may still be necessary to determine appropriate use.

\section{Conclusions}

FDA-mandated REMS programs have changed the landscape of pharmaceutical care and delivery and will continue to develop this area of care. Requirements associated with REMS implementation, the medication distribution process (especially ETASU programs), patient confidentiality, and incorporation into clinical guidelines and protocols raise operational questions that MCOs have not yet fully addressed. Benefits for MCOs include additional health outcomes research data; a reduction in the need for $\mathrm{MCO}$-developed utilization management protocols; heightened fraud, waste, and abuse prevention; and potentially fewer catastrophic adverse events. Given the nature and mix of drugs included in REMS programs, MCOs have no choice but to incorporate REMS programs for necessary medications into their processes. 


\section{Authors}

Members of the Special Projects Committee of the Academy of Managed Care Pharmacy in 2010-2011 wrote the manuscript, and the AMCP committee in 2011-2012 revised the manuscript. The primary author was GAURANG GANDHI, PharmD, MHA. Additional contributors were ASHLEY CHON, PharmD; NIK JOHNSON, CPhT; PHYLLIS A. KIDDER, PharmD; PETER LEE, PharmD, MBA; KEVIN LEUNG, PharmD, BCPS; INGRID MA, RPh, PharmD; STACEY NESS, PharmD; ELIZABETH SAMPSEL, PharmD, MBA, BCPS; MARISSA SCHLAIFER, MS, RPh; RANDALL SEIFERT, BS, PharmD; and DEBORA B. STERNAMAN, BS, PharmD. INGRID MA served as chairperson of the committee in 2010-2011, and KALINDI RAVAL, PharmD, was the chairperson in 2011-2012.

AUTHOR CORRESPONDENCE: Marissa Schlaifer, MS, RPh, Academy of Managed Care Pharmacy, 100 North Pitt St., Ste. 400, Alexandria, VA 22314. Tel.: 703.683.8416;

E-mail: mschlaifer@amcp.org.

\section{DISCLOSURES}

There was no external funding for this commentary.

\section{REFERENCES}

1. U.S. Food and Drug Administration. Regulatory information: full text of FDAAA law. Public Law 110-85. Updated August 17, 2009. Available at: http://www.fda.gov/RegulatoryInformation/Legislation/FederalFoodDrug andCosmeticActFDCAct/SignificantAmendmentstotheFDCAct/Foodand DrugAdministrationAmendmentsActof2007/FullTextofFDAAALaw/default. htm. Accessed March 3, 2012

2. U.S. Food and Drug Administration. Regulatory information: Food and Drug Administration Amendment Act (FDAAA) of 2007. Updated December 2, 2011. Available at: http://www.fda.gov/RegulatoryInformation/Legislation/ FederalFoodDrugandCosmeticActFDCAct/SignificantAmendmentstothe FDCAct/FoodandDrugAdministrationAmendmentsActof2007/default.htm. Accessed March 3, 2012.

3. American Pharmacists Association. White paper on designing a risk evaluation and mitigation strategies (REMS) system to optimize the balance of patient access, medication safety, and impact on the health care system. J Am Pharm Assoc (2003). 2009;49(6):729-43. Available at: http://www. pharmacist.com/AM/Template.cfm?Section=Home2\&TEMPLATE=/CM/ ContentDisplay.cfm\&CONTENTID=23635. Accessed March 3, 2012

4. Baciu A, Stratton K, Burke SP, eds. Institute of Medicine Committee on the Assessment of the U.S. Drug Safety System. The Future of Drug Safety: Promoting and Protecting the Health of the Public. Washington, DC: The National Academies Press; 2007:15-30. Available at: http://www.nap.edu/ catalog.php?record_id=11750. Accessed March 3, 2012.

5. U.S. Food and Drug Administration. Drugs: Vioxx (rofecoxib) questions and answers. September 30, 2004. Updated December 30, 2009. Available at: http://www.fda.gov/Drugs/DrugSafety/PostmarketDrugSafetyInformation forPatientsandProviders/ucm 106290.htm. Accessed March 3, 2012.

6. U.S. Food and Drug Administration. FDA issues Public Health Advisory on Tysabri, a new drug for MS. February 28, 2005. Updated June 22, 2009. Available at: http://www.fda.gov/NewsEvents/Newsroom/Press

Announcements/2005/ucm108413.htm. Accessed March 3, 2012.

7. Franks ME, Macpherson GR, Figg WD. Thalidomide. Lancet. 2004;363 (9423):1802-11.
8. U.S. Food and Drug Administration. Guidance for industry: format and content of proposed Risk Evaluation and Mitigation Strategies (REMS), REMS assessments, and proposed REMS modifications. September 2009. Available at: http://www.fda.gov/downloads/Drugs/GuidanceCompliance RegulatoryInformation/Guidances/UCM184128.pdf. Accessed March 3, 2012.

9. U.S. Food and Drug Administration. Guidance for industry: medication guides_distribution requirements and inclusion in Risk Evaluation and Mitigation Strategies (REMS). November 2011. Available at: http://www. fda.gov/downloads/Drugs/GuidanceComplianceRegulatoryInformation/ Guidances/UCM244570.pdf. Accessed March 3, 2012.

10. U.S. Food and Drug Administration. Ampyra (dalfampridine) extended release tablets. Risk Evaluation and Mitigation Strategy (REMS). Accorda Therapeutics. January 19, 2010. Available at: http://www.accessdata.fda. gov/drugsatfda_docs/label/2010/022250s000REMS.pdf. Accessed March 2, 2012.

11. U.S. Food and Drug Administration. Regulatory Information: questions and answers on the Federal Register notice on drugs and biological products deemed to have Risk Evaluation and Mitigation Strategies. Updated June 18, 2009. Available at: http://www.fda.gov/RegulatoryInformation/Legislation/ FederalFoodDrugandCosmeticActFDCAct/SignificantAmendmentstothe FDCAct/FoodandDrugAdministrationAmendmentsActof2007/ucm095439. htm. Accessed March 3, 2012.

12. U.S. Food and Drug Administration. Revlimid (lenalidomide). Risk Evaluation and Mitigation Strategy (REMS). Celgene Corporation. July 29, 2009. Available at: http://www.fda.gov/downloads/Drugs/DrugSafety/ PostmarketDrugSafetyInformationforPatientsandProviders/UCM222644.pdf. Accessed March 3, 2012.

13. U.S. Food and Drug Administration. Approved Risk Evaluation and Mitigation Strategies (REMS). Updated February 15, 2012. Available at: http://www.fda.gov/Drugs/DrugSafety/PostmarketDrugSafetyInformationfor PatientsandProviders/ucm111350.htm. Accessed March 3, 2012.

14. U.S. Food and Drug Administration. Questions and answers: FDA requires a Risk Evaluation and Mitigation Strategy (REMS) for long-acting and extended-release opioids. Updated April 19, 2011. Available at: http:// www.fda.gov/Drugs/DrugSafety/InformationbyDrugClass/ucm251752.htm. Accessed March 3, 2012.

15. U.S. Food and Drug Administration. Blueprint for prescriber continuing education program. October 25, 2011. Available at: http://www.fda.gov/ downloads/Drugs/DrugSafety/InformationbyDrugClass/UCM277916.pdf. Accessed March 3, 2012.

16. Abstral (fentanyl) REMS home page. ProStrakan. December 2011. Available at: https://www.abstralrems.com/AssureUI/AssureUI/home.action. Accessed March 3, 2012.

17. U.S. Food and Drug Administration. Actemra (tocilizumab). Risk Evaluation and Mitigation Strategy (REMS). Genentech, Inc. Updated April 15, 2011. Available at: http://www.fda.gov/downloads/Drugs/DrugSafety/ PostmarketDrugSafetyInformationforPatientsandProviders/UCM202044.pdf. Accessed March 3, 2012.

18. Actiq (oral transmucosal fentanyl citrate) prescribing information. Cephalon. July 2011. Available at: http://www.actiq.com/pdf/actiq_package_insert_4_5_07.pdf. Accessed March 3, 2012.

19. U.S. Food and Drug Administration. BLA 103000 Botox/Botox Cosmetic (OnabotulinumtoxinA). Allergan, Inc. Updated August 2011. Available at: http://www.fda.gov/downloads/Drugs/DrugSafety/PostmarketDrugSafety InformationforPatientsandProviders/UCM187530.pdf. Accessed March 3, 2012.

20. U.S. Food and Drug Administration. Brilinta (ticagrelor). Risk Evaluation and Mitigation Strategy (REMS). AstraZeneca. July 20, 2011. Available at: http://www.fda.gov/downloads/Drugs/DrugSafety/ PostmarketDrugSafetyInformationforPatientsand/Providers/UCM264004. pdf. Accessed March 3, 2012. 
21. U.S. Food and Drug Administration. Caprelsa (vandetanib). Risk Evaluation and Mitigation Strategy (REMS). AstraZeneca. Updated June 22, 2011. Available at: http://www.fda.gov/downloads/Drugs/DrugSafety/ PostmarketDrugSafetyInformationforPatientsandProviders/UCM25344l.pdf. Accessed March 3, 2012.

22. U.S. Food and Drug Administration. Lumizyme (alglucosidase alfa). Risk Evaluation and Mitigation Strategy (REMS). Genzyme. Updated September 2011. Available at: http://www.fda.gov/downloads/Drugs/DrugSafety/ PostmarketDrugSafetyInformationforPatientsandProviders/UCM213511.pdf. Accessed March 3, 2012

23. U.S. Food and Drug Administration. Mifeprex (mifepristone). Risk Evaluation and Mitigation Strategy (REMS). Danco Laboratories. June 8, 2011. Available at: http://www.fda.gov/downloads/Drugs/DrugSafety/ PostmarketDrugSafetyInformationforPatientsandProviders/UCM258412.pdf. Accessed March 3, 2012.

24. U.S. Food and Drug Administration. Nulojix (belatacept). Risk Evaluation and Mitigation Strategy (REMS). Bristol-Myers Squibb Company. June 15, 2011. Available at: http://www.fda.gov/downloads/Drugs/ DrugSafety/PostmarketDrugSafetyInformationforPatientsandProviders/ UCM261934.pdf. Accessed March 3, 2012.

25. U.S. Food and Drug Administration. Perforomist (formoterol fumarate). Risk Evaluation and Mitigation Strategy (REMS). Dey Pharma. February 1, 2011. Available at: http://www.fda.gov/downloads/Drugs/DrugSafety/ PostmarketDrugSafetyInformationforPatientsandProviders/UCM245184.pdf. Accessed March 3, 2012

26. U.S. Food and Drug Administration. Prolia (denosumab). Risk Evaluation and Mitigation Strategy (REMS). Amgen, Inc. Updated September 2011. Available at: http://www.fda.gov/downloads/Drugs/DrugSafety/ PostmarketDrugSafetyInformationforPatientsandProviders/UCM214383.pdf Accessed March 3, 2012

27. U.S. Food and Drug Administration. Tikosyn (dofetilide). Risk Evaluation and Mitigation Strategy (REMS). Pfizer, Inc. July 11 , 2011. Available at: http://www.fda.gov/downloads/Drugs/DrugSafety/ PostmarketDrugSafetyInformationforPatientsandProviders/UCM266277.pdf. Accessed March 3, 2012

28. U.S. Food and Drug Administration. Yervoy (ipilimumab). Risk Evaluation and Mitigation Strategy (REMS). Bristol-Myers Squibb Company. March 25, 2011. Available at: http://www.fda.gov/downloads/Drugs/ DrugSafety/PostmarketDrugSafetyInformationforPatientsandProviders/ UCM249435.pdf. Accessed March 3, 2012.

29. U.S. Food and Drug Administration. FDA and manufacturers of Accutane and its generics to implement iPLEDGE program on March 1, 2006. Updated June 18, 2009. Available at: http://www.fda.gov/NewsEvents/ Newsroom/PressAnnouncements/2006/ucm108605.htm. Accessed March 3, 2012 .
30. U.S. Food and Drug Administration. Tracleer (bosentan). Risk Evaluation and Mitigation Strategy (REMS). Actelion. July 28, 2009. Available at: http://www.accessdata.fda.gov/drugsatfda_docs/ label/2009/021290s012REMS.pdf. Accessed March 3, 2012.

31. HealthBridge Pharma \& Biotech. Access to data for millions of patients leads to higher quality Risk Evaluation \& Mitigation Strategies (REMS) programs and better outcomes. Available at: http://www.thehealthbridgesolution.com/solutions/healthbridge-pharma-biotechs-access-data-millionspatients-leads-higher-quality-risk-evalu. Accessed March 12, 2011.

32. U.S. Food and Drug Administration. Letairis (ambrisentan) Risk Evaluation and Mitigation Strategy (REMS). Updated February 2012. Available at: http://www.fda.gov/downloads/Drugs/DrugSafety/ PostmarketDrugSafetyInformationforPatientsandProviders/UCM164969.pdf. Accessed March 12, 2012.

33. U.S. Food and Drug Administration. Epogen/Procrit (epoetin alfa) injection. Risk Evaluation and Mitigation Strategy (REMS). Amgen Inc. June 24, 2011. Available at: http://www.fda.gov/downloads/Drugs/DrugSafety/ PostmarketDrugSafetyInformationforPatientsandProviders/UCM200105.pdf. Accessed March 3, 2012.

34. U.S. Food and Drug Administration. Aranesp (darbepoetin alfa) injection. Risk Evaluation and Mitigation Strategy (REMS). Amgen Inc. June 24, 2011. Available at: http://www.fda.gov/downloads/Drugs/DrugSafety/ PostmarketDrugSafetyInformationforPatientsandProviders/UCM200104.pdf. Accessed March 3, 2012

35. No authors listed. Plans can view REMS as barriers to care or tools for better management, outcomes. Specialty Pharmacy News. 2010;6(3):1,9-12. Available at: http://aislicenses.com/NSPN/fetchPdf.php?folder=SPN_ pdf\&name=spn0310. Accessed March 3, 2012.

36. No authors listed. REMs for drugs already on market will mean additional challenges for stakeholders. Specialty Pharmacy News. 2010;6(3):10. Available at: http://aislicenses.com/NSPN/fetchPdf.php? folder=SPN_pdf\&name=spn0310. Accessed March 3, 2012.

37. U.S. Food and Drug Administration. Avandia (rosiglitazone maleate). Risk Evaluation and Mitigation Strategy (REMS). GlaxoSmithKline. November 2011. Available at: http://www.fda.gov/downloads/drugs/drugsafety/postmarketdrugsafetyinformationforpatientsandproviders/ucm 255624 pdf. Accessed March 3, 2012.

38. U.S. Food and Drug Administration. FDA drug safety communication: new risk factor for progressive multifocal leukoencephalopathy (PML) associated with Tysabri (natalizumab). January 20, 2012. Available at: http:// www.fda.gov/Drugs/DrugSafety/ucm288186.htm. Accessed March 3, 2012.

39. Nishida L, Kephart C. How to integrate FDA Risk Evaluation and Mitigation Strategy requirements into formulary management. Atlantic Information Services. Webinar conducted June 2, 2010.

40. Amprya (dalfampridine) prescribing information. January 2010. Acorda Therapeutics. Available at: http://ampyra.com/local/files/PI.pdf. Accessed March 3, 2011. 